\title{
Modeling of Geomechanical Processes Case of Uneven Settling of Foundations Constructions
}

\author{
Sokolov Mikhail V., , Prostov Sergey M. ${ }^{\mathrm{b}}$ \\ T. F. Gorbachev Kuzbass State Technical University \\ Kemerovo, Russian Federation \\ ae-mail: ea-sokolov42@mail.ru, be-mail: psm.kem@mail.ru
}

\begin{abstract}
The results of forecasting the development of uneven settlement of buildings according to computer simulation of soil foundations with various geological structure using the software package "Alterra». The regularities of uneven vertical displacements and changes in the stress-strain state of the soil foundation were identified. The estimated data were compared to the results of the real object survey and monitoring.
\end{abstract}

Keywords - uneven settlement, foundation, soil, computer simulation, stress-strain state

\section{INTRODUCTION}

The problem of prevention of nonuniform vertical movements (settlements) of the foundations is very actual both in construction and in mining industries now. The reasons of non-uniform settlements are insufficient accuracy of calculations in designing of the foundations for large typical construction buildings and structures [1], [2]; features of a geological structure of the foundation (look, state and bedding of soils) [3], climatic conditions [4] and technogenic factor ("overload" of building, soaking of soils basis, lack of planned overhauling) [5]. The monitoring of vertical movements in most cases covering the period of 5 and more years is performed for prevention of nonuniform movements. Therefore, an actual problem of the modern construction is the possibility of prediction of deformation processes in the soil foundations on the basis of their numerical modeling [6] at various technogenic influences [7] that will provide reduction of terms of monitoring. The solution of the problem is achievable by means of the modern program complexes for
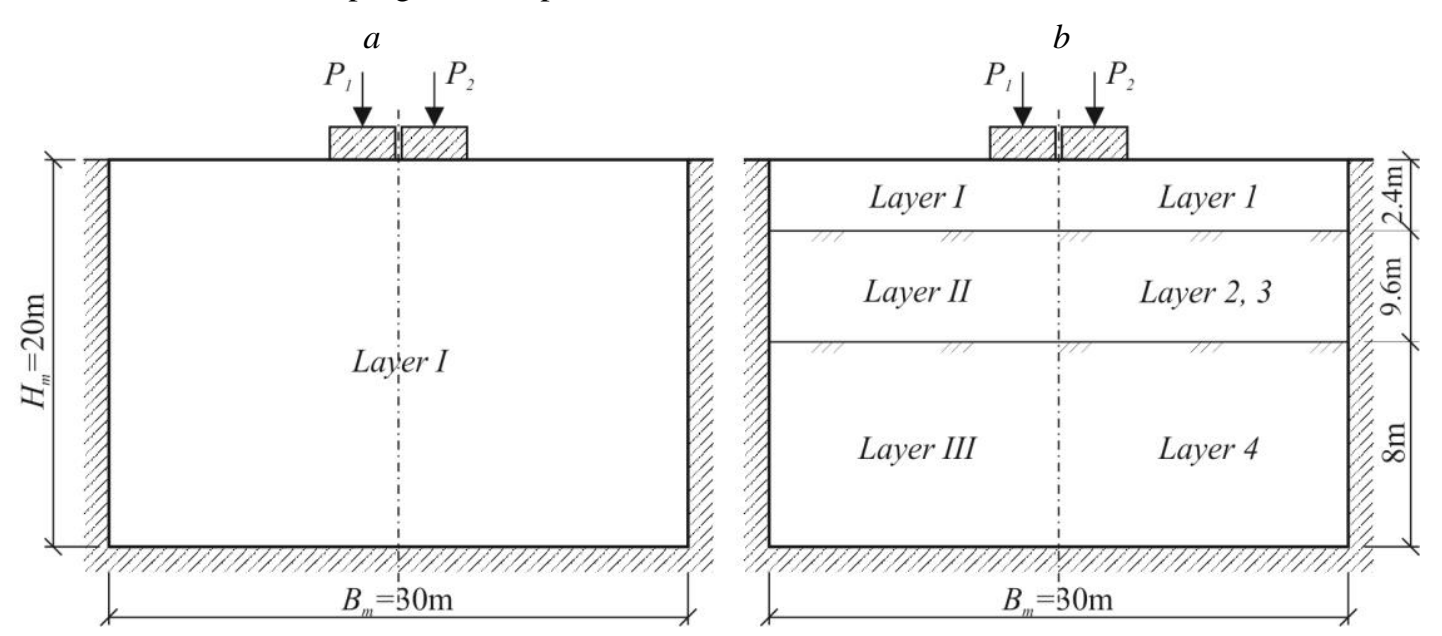

Fig. 1. Calculation model for loading of homogeneous $(a)$ and inhomogeneous $(b)$ soil bodies

geomechanical calculations [8] [9]. The geomechanical computer models of the foundations developed by a finite element method allow to review the "foundation-soil" system at different stages of construction and operation of the structure [10] [11], to study in detail the processes of vertical movements in time and formations of stress-strained state of the soil body [12].

The conducted researches on computer prediction of nonuniform settlements consisted in stage-by-stage studying of soil bodies of various structure and application of the obtained data on an actual object. The modeling of nonuniform settlements was made with application of "Alterra" software complex for geotechnical calculations provided free for non-profit use by the InzhProyektStroy company. The purpose of the simulation was to establish interrelations between the foundation settlement and factors influencing their emergence; to study the stress-strained state of a soil foundation of a homogeneous and nonuniform structure at nonuniform vertical load, and to develop recommendations on fixing the soil foundation for prevention of nonuniform settlements.

\section{MATERIALS AND METHODS}

Basic methodical positions of building calculation models are presented in the works of authors [13-15]. The analysis took into account the simulation results for different conditions presented in [15-21], where the characteristic features of the soil body condition changes were noted. 
In the primary stage of the research, the model of loading the homogeneous soil body by two closely spaced stamps was reviewed. The mechanical parameters were the following: the deformation module $E=5 \mathrm{MPa}$; Poisson's ratio $v=0.36$; angle of internal friction $\varphi=18^{\circ}$; specific cohesion $C=5 \mathrm{kPa}$; the average density $\rho=1750 \mathrm{~kg} / \mathrm{m}^{3}$ (Fig. 1, $a$ ). The parameters of stamp: deformation module $E=2000 \mathrm{MPa}$; Poisson's ratio $v=0.15$; the average density $\rho_{f}=2500 \mathrm{~kg} / \mathrm{m}^{3}$; width $b_{f}=1 \mathrm{~m}$; height $h_{f}=0.5 \mathrm{~m}$. The uneven loading of the soil was achieved by setting different load ratios to the stamps $P_{2} / P_{1}$ similar to the approach described in [20].

In order to assess the impact of structural inhomogeneities of the foundation, the base of models was established optimized according to the principles set forth in [21] with $P_{l}=60 \mathrm{kN}$, ratios $P_{2} / P_{l}=1.0,1.5,2.0$ and a three-layer structure of the foundation (Fig. $1, b$ ) formed by soils with different physical and mechanical properties (Table 1) corresponding to the properties and structure of a real object foundation which is discussed below.

TABLE I. PHYSICAL AND MECHANICAL PROPERTIES OF FOUNDATION SOIL

\begin{tabular}{|c|c|c|c|c|c|c|c|c|c|c|c|}
\hline \multicolumn{6}{|c|}{ Inhomogeneous foundation } & \multicolumn{6}{|c|}{ The real object } \\
\hline \multirow[b]{2}{*}{$\begin{array}{l}\text { Layer } \\
\text { name }\end{array}$} & \multicolumn{5}{|c|}{$\begin{array}{c}\text { Physical and mechanical } \\
\text { properties }\end{array}$} & \multirow[b]{2}{*}{$\begin{array}{l}\text { Layer } \\
\text { name }\end{array}$} & \multicolumn{5}{|c|}{$\begin{array}{c}\text { Physical and mechanical } \\
\text { properties }\end{array}$} \\
\hline & $\begin{array}{l}\dot{0} 0 \\
\tilde{v} \\
\hat{s}\end{array}$ & $\frac{0}{v}$ & $\underset{\Sigma}{\Xi}$ & $\frac{3}{2}$ & $>$ & & $\begin{array}{l}\dot{\infty} \\
\stackrel{0}{0} \\
\dot{2}\end{array}$ & $\frac{\sum^{2}}{4}$ & 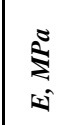 & $\frac{\text { so }}{\stackrel{3}{E}}$ & $>$ \\
\hline $\begin{array}{l}\text { Layer } \\
\text { I }\end{array}$ & 18 & 5 & 5 & 1910 & 0.39 & $\begin{array}{l}\text { Layer } \\
1\end{array}$ & 18 & 10 & 5 & 1950 & 0.36 \\
\hline \multirow{2}{*}{$\begin{array}{l}\text { Layer } \\
\text { II }\end{array}$} & \multirow{2}{*}{18} & \multirow{2}{*}{10} & \multirow{2}{*}{14} & \multirow{2}{*}{1910} & \multirow{2}{*}{0.29} & $\begin{array}{l}\text { Layer } \\
2\end{array}$ & 19 & 27.5 & 15.4 & 1910 & 0.28 \\
\hline & & & & & & $\begin{array}{l}\text { Layer } \\
3\end{array}$ & 17 & 14 & 11.4 & 1930 & 0.30 \\
\hline $\begin{array}{l}\text { Layer } \\
\text { III }\end{array}$ & 18 & 15 & 8 & 1850 & 0.29 & $\begin{array}{l}\text { Layer } \\
4\end{array}$ & 18 & 14.3 & 7.4 & 1850 & 0.28 \\
\hline
\end{tabular}

$a$
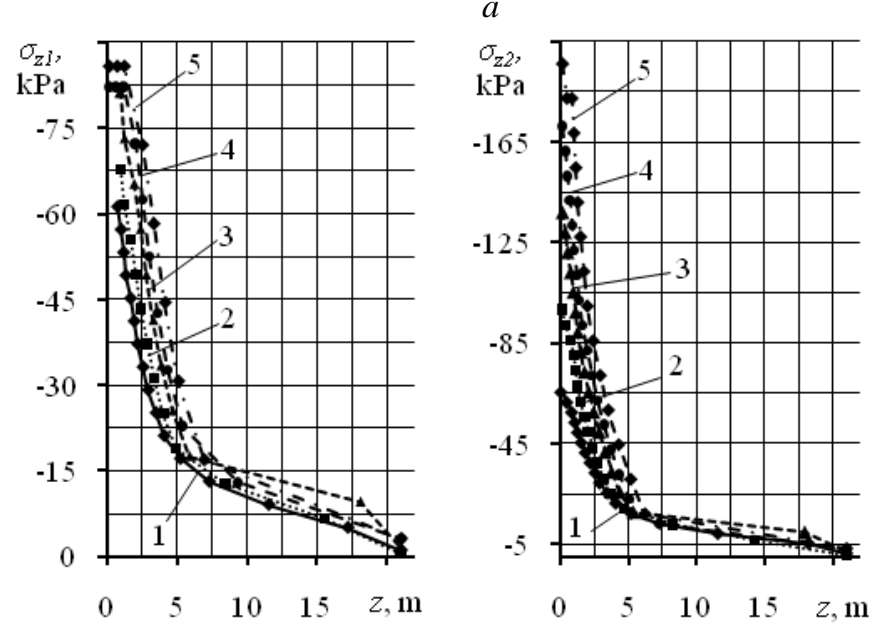

\section{RESULTS AND DISCUSSION}

As a result of the calculations, the close-to-linear dependence was set of the vertical displacements (settlements) $S_{1} / S_{2}$ under the corresponding stamps on the ratio of loads $P_{2} / P_{1}$ (Fig. 2). Violation of the linear dependence at $P_{1}=80 \mathrm{kN}$ and $P_{2} / P_{1}=3.0$ was caused by compression strength failure of the soil and the development of large plastic deformations.

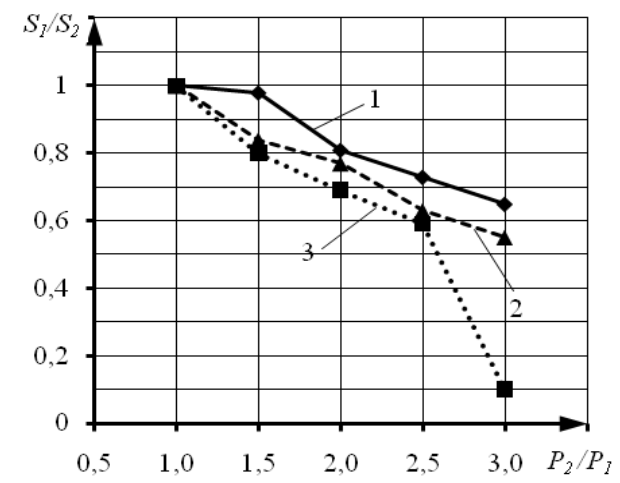

Fig. 2. The dependence of vertical displacements (settlement) under the stamps $S_{I} / S_{2}$ on the ratio of the loads on the stamps $P_{2} / P_{I}$ at $P_{l}$ is equal to:

$1-P_{l}=40 \mathrm{kN} ; 2-P_{l}=60 \mathrm{kN} ; 3-P_{l}=80 \mathrm{kN}$

The vertical stresses under the stamps $\sigma_{z 1}$ and $\sigma_{z 2}$ decrease monotonically with increasing depth of the model $z$, while their values are many times higher under stamp number 2 (Fig. 3,a). In the analysis of horizontal stresses $\sigma_{x 1}$ and $\sigma_{x 2}$ it was identified that at the ratio $P_{2} / P_{1}=1$ the stress decreases with depth, but when $P_{2} / P_{1}=1.5 \ldots 3$ the formation of tensile stress zone was noted from the depth $=3 \mathrm{~m}$, and the stress concentration and the width of this zone depend on load $P_{1}$ and the ratio $P_{2} / P_{1}$. At high values $P_{2} / P_{1}$ under the most loaded stamp the zone of maximum compressive stress is formed in the range $z=3 \mathrm{~m} \quad$ (Fig. 3, $b$ ).

\section{$b$}

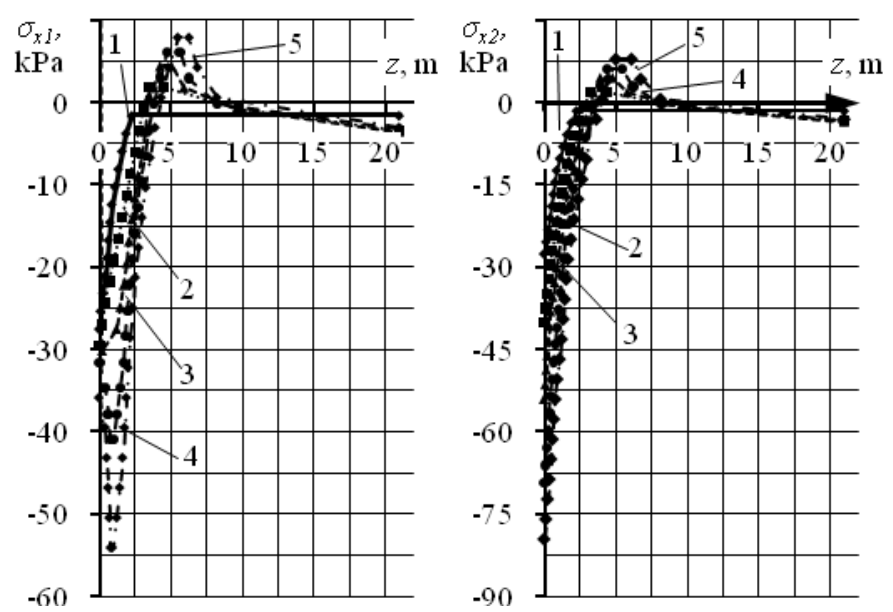

Fig. 3. Dependence of vertical $\sigma_{z}(a)$ and horizontal $\sigma_{x}(b)$ stresses under the stamps on the depth of the soil body $z$ with loads $P_{1}=60 \mathrm{kN}$ and ratios of loads on the stamps $P_{2} / P_{1}$ equal to:

$1-P_{2} / P_{1}=1 ; 2-P_{2} / P_{1}=1.5 ; 3-P_{2} / P_{1}=2 ; 4-P_{2} / P_{1}=2.5 ; 5-P_{2} / P_{1}=3$ 
The detailed analysis showed that the effect of closely set stamps in the presence of one more loaded on the stress state of the soil body is as follows:

- $\quad$ increase in absolute values of stresses $\sigma_{z 1}$ and $\sigma_{z 2}$ without change in the character of their distributions with the increase of ratios $P_{2} / P_{1}$;

- the dependence of the peak values $\sigma_{x}$ in the zones of tensile stresses under both stamps on the ratio $P_{2} / P_{1}$;

- the formation of the concentration zone of compressive horizontal stresses $\sigma_{x}$ under the less loaded stamp with increase of the load and relationships $P_{2} / P_{1}$.

The zones of horizontal tensile stresses, most dangerous from the point of breach of grounds stability, are distributed over the depth of the model in the range $z=3 \ldots 8 \mathrm{~m}$. To quantify the emerging abutment pressure zone, the following integrated features are introduced: distance to the point of maximum stresses; coefficient of concentration kc:

$$
k_{c}=\frac{\sigma_{x i, \max }}{\sigma_{x i, \text { lost }}},
$$

where: $\sigma_{x i \text { max }}$ is peak (maximum) stresses in the zone of stress concentration, $\mathrm{kPa} ; \sigma_{x i, l o s t}$ is conditional stresses in the untouched part of the soil body, $\mathrm{kPa}$.

The character of the maximum tensile stress zone development and the dependence of the coefficient $k_{c}$ on the ratios $P_{2} / P_{1}$ are shown in Fig. $4, b$.
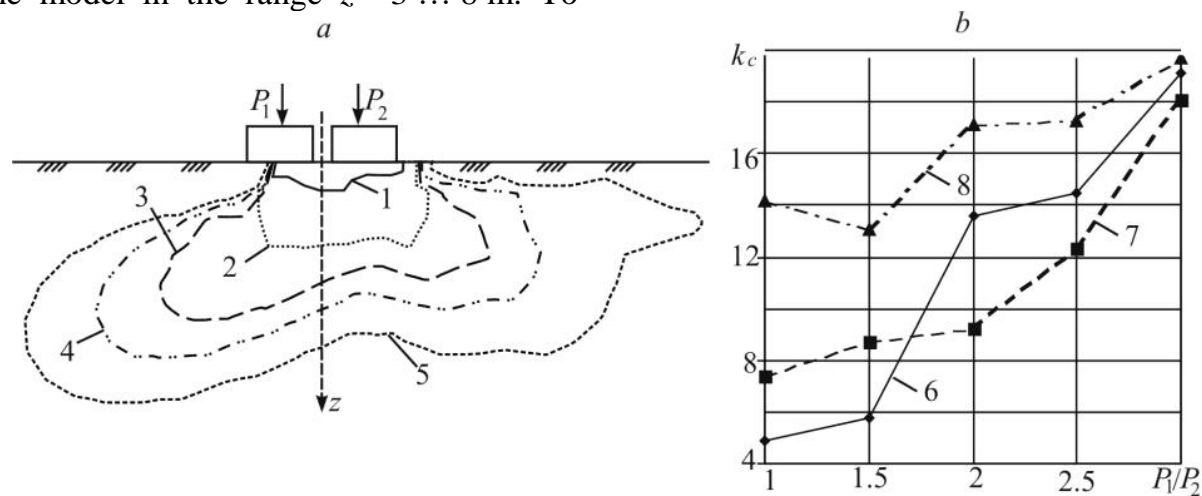

Fig. 4. Form of formed zones of tensile stress concentration $(a)$ and the dependence of the concentration coefficient $k_{c}$ on the ratio of loads on the stamps $P_{2} / P_{I}(b)$ and the value of $P_{1}$. $1-P_{2} / P_{1}=1 ; 2-P_{2} / P_{l}=1.5 ; 3-P_{2} / P_{l}=2 ; 4-P_{2} / P_{l}=2.5 ; 5-P_{2} / P_{l}=3$; $6-P_{l}=40 \mathrm{kN} ; 7-P_{l}=60 \mathrm{kN} ; 8-P_{l}=80 \mathrm{kN}$
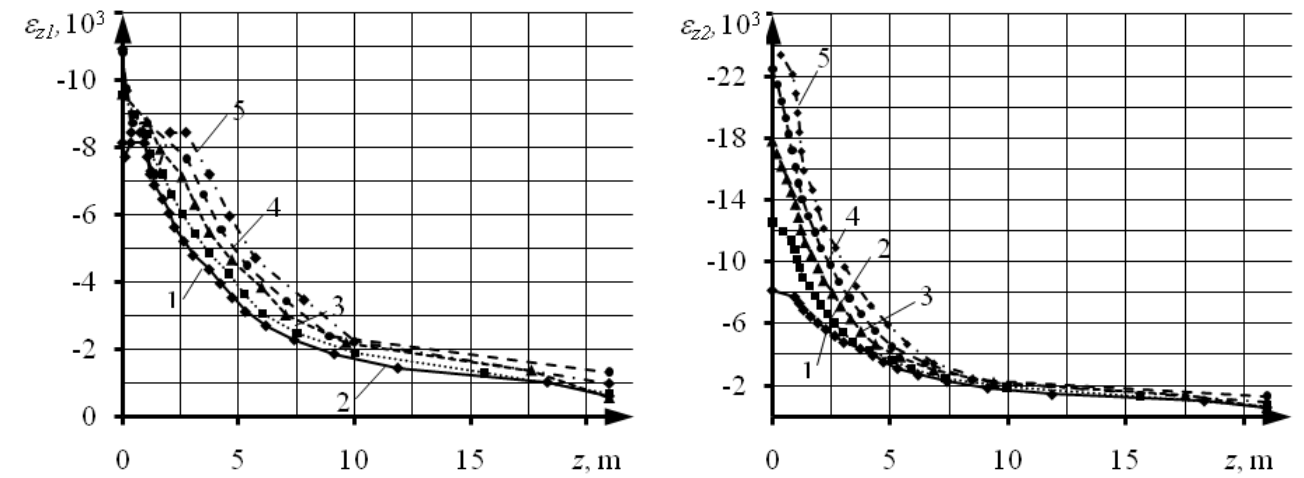

Fig. 5. Dependence of the vertical deformations $\varepsilon_{z I}$ and $\varepsilon_{z 2}$ of the soil body on the depth of the body soil $z$ at loads $P_{l}=80 \mathrm{kN}$ and the ratios on the stamps $P_{2} / P_{l}$ equal to:

$$
1-P_{2} / P_{1}=1 ; 2-P_{2} / P_{1}=1.5 ; 3-P_{2} / P_{1}=2 ; 4-P_{2} / P_{I}=2.5 ; 5-P_{2} / P_{1}=3
$$

The character of development of the vertical deformation $\varepsilon_{z}$ repeats to a great extent the character of the graphs $\sigma_{z}(z)$ shown in Fig. 3, $a$ : deformations $\varepsilon_{z 1}$ and $\varepsilon_{z 2}$ decrease monotonically with the depth of model $z$ without formation of the zones of anomalous deformations. In the range of $z=0,5 \ldots 2,0 \mathrm{~m}$ a chaotic change $\varepsilon_{z 1}$ is noted as a result of influence of close standing stamps (Fig. 5).

A much more complex character is identified in the development of horizontal deformations $\varepsilon_{x}$. From the dependency $\varepsilon_{x 1}(z)$ and $\varepsilon_{x 2}(z)$ follows that at loading occurs lateral displacement of soil in the away from the axis of symmetry stamps in two opposite directions (Fig. 6).

In the analysis of dependences $\varepsilon_{x l}(z)$ and $\varepsilon_{x 2}(z)$ for different ratios $P_{2} / P_{1}$ the zone of maximum horizontal deformation is identified, located in the range $z=0.5 \ldots 10 \mathrm{~m}$. Under the influence of a more loaded stamp the depth of maximum values location increases and their size is monotonically increasing. With increasing ratio $P_{2} / P_{1}$, the asymmetry of horizontal deformation distributions becomes more pronounced (Fig. 7). 

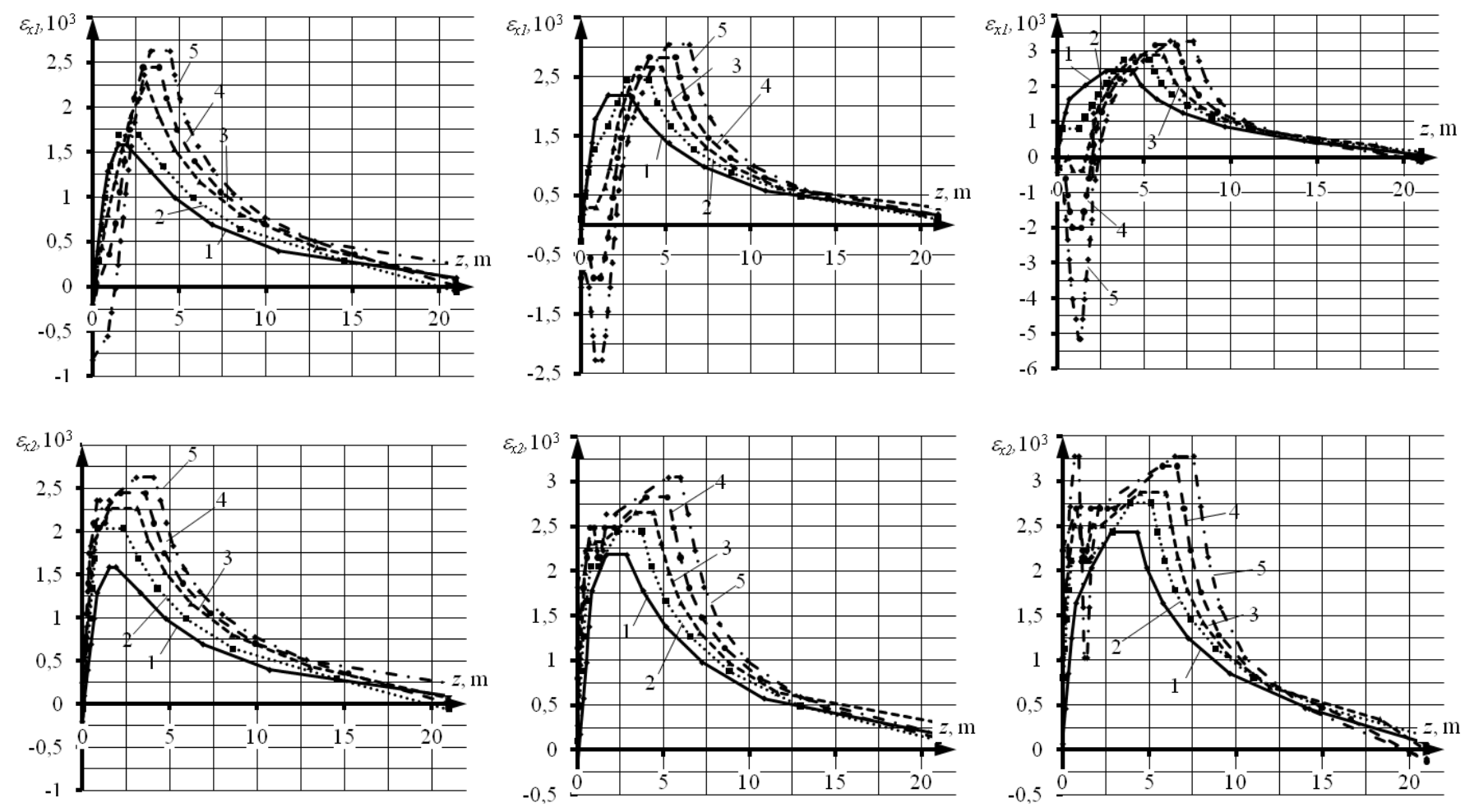

Fig. 6. Dependence of horizontal elastic deformations of the soil body on the depth of the soil body $z$ at loads $P_{l}=40 \mathrm{kN}(a), P_{l}=60 \mathrm{kN}(b), P_{l}=80 \mathrm{kN}(c)$

and the ratios of loads on the stamps $P_{2} / P_{1}$ equal to: $1-P_{2} / P_{l}=1 ; 2-P_{2} / P_{l}=1.5 ; 3-P_{2} / P_{l}=2 ; 4-P_{2} / P_{l}=2.5 ; 5-P_{2} / P_{l}=3$

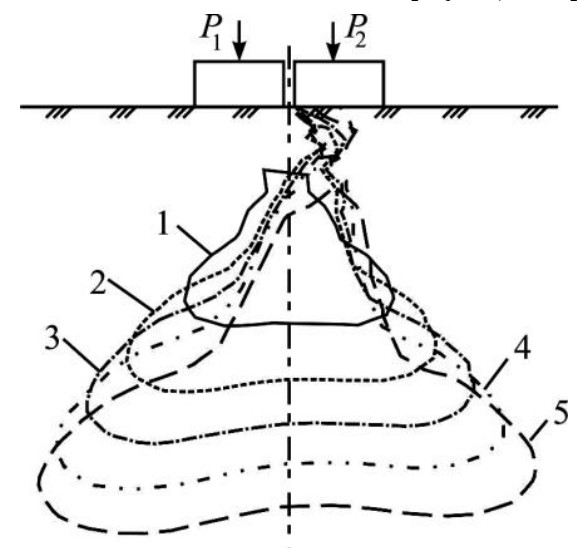

Fig. 7. Distribution of zones of maximum horizontal deformations at $P_{2} / P_{1}$ equal to:

$1-P_{2} / P_{1}=1 ; 2-P_{2} / P_{1}=1.5 ; 3-P_{2} / P_{1}=2 ; 4-P_{2} / P_{l}=2.5 ; 5-P_{2} / P_{1}=3$

The main results of the analysis of the databases of modeling results of unequally loaded inhomogeneous foundation (see. Illustration in Fig. 1, $b$ ) are shown in Fig. 8.

The peculiarity of the stress-strain state of the layered ssoil foundation under stamps consists in that the maximum horizontal deformations localize in the boundary of the first weak layer $(z=2,4 \mathrm{~m})$. This point corresponds to bending of the graphs of vertical deformations $\varepsilon_{z}$ and the appearance of horizontal tensile stress $\sigma_{x}$.
The influence of the inhomogeneous structure of the soil foundation on the distribution $\varepsilon_{x}(z)$ is expressed in the concentration of deformations within the boundaries of the weak (upper) layer and the subsequent monotonic decrease without the formation of the characteristic bends. The changing nature of distribution $\varepsilon_{x I}(z)$ and decrease in tensile strain $\varepsilon_{x I}$ in the boundaries of the first layer is a result of influence of the neighboring stamp.

In order to test the adequacy of the model under study, the comparison of the calculated data was carried out with the results of experimental studies of production at the facility Ltd. "NOOTSENTR" (Kemerovo city, village Sukhovsky). The experimental facility was a five-story building in a poor condition due to unacceptable deformations of the structure and the formation of cracks.

For instrumental observations on the outer walls from the ground level floor of the object there were installed 23 contour stands (the deformation marks) and 2 settlement probesfixed ground rapper to a depth of $8 \mathrm{~m}$ (Fig. 9, a). Monitoring of changes in marks was conducted for 400 days (Fig. 9, b).

The average value of the settlement speed of the foundation over the observation period was $V_{c p}=$ $=0.132 \mathrm{~mm} /$ day. Uneven settlement along the longitudinal axis $x$ of the structure at the early stage of observations was 60\%: the greatest deformation of the foundation was observed in the interval $x=0-25 \mathrm{~m}$, the least - in the interval $x=43-$ $70 \mathrm{~m}$ (Fig. 9, c). 

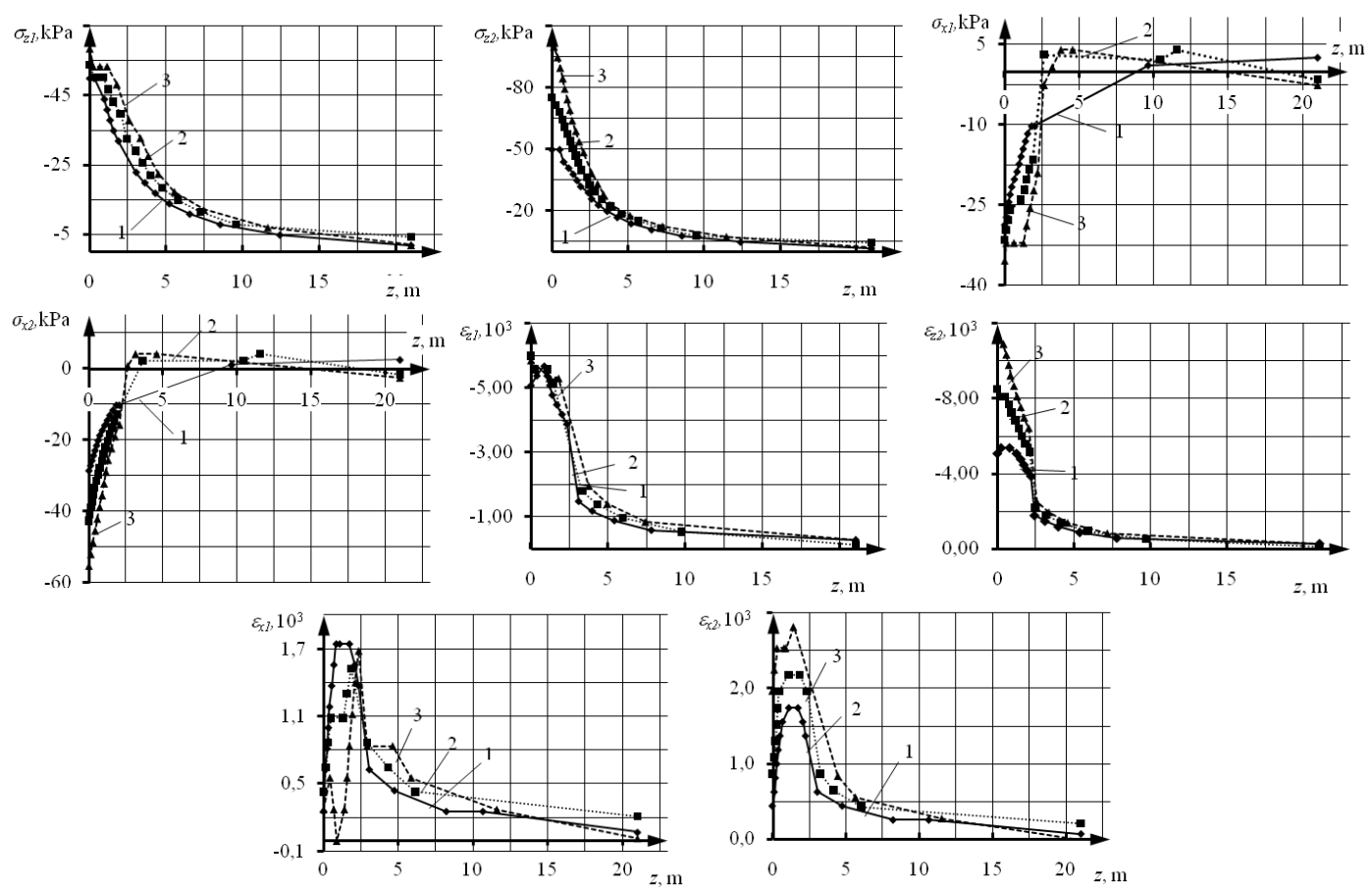

Fig. 8. Dependence of the vertical $\sigma_{z}$ and horizontal $\sigma_{x}$ stresses, the vertical $\varepsilon_{z}$ and horizontal $\varepsilon_{x}$ deformations under stamps from the depth of the soil body $z$ at load $P_{1}=60 \mathrm{kN}$ and the ratios of loads on the stamps $P_{2} / P_{1}$ equal to: $1-P_{2} / P_{1}=1 ; 2-P_{2} / P_{1}=1.5 ; 3-P_{2} / P_{1}=2 ; 4-P_{2} / P_{1}=2.5 ; 5-P_{2} / P_{l}=3$
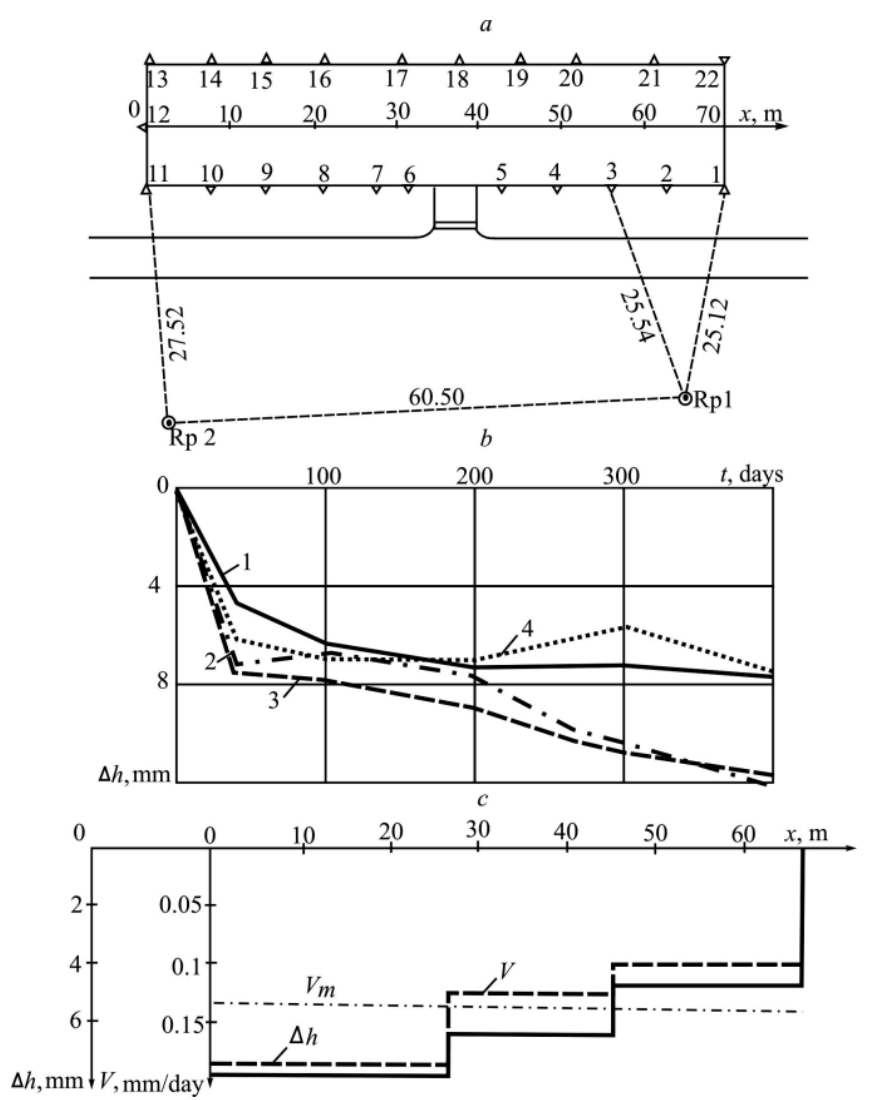

Fig. 9. The scheme of the object $(a)$; graphs of changes of vertical deformation $\Delta h(b)$ in time; graphs of changes of average values of strain $\Delta h$ and foundation strain rates $V$ along the longitudinal axis $x$ of the structure $(c)$ : 1 - benchmark no. $2(x=62 \mathrm{~m}) ; 2$ - № 5 (43 m); 3 - № $11(0 \mathrm{~m}) ; 4$ - № 17

(31m); $\Delta$ - outline benchmarks; $\odot$ - ground settlement benchmarks; $\mathrm{O} x$ - the longitudinal axis
When predicting the deformation of the object the foundation of the building was modeled along the longitudinal axis. From the designing point of view, this was a prefab building with self-supporting and load-bearing brick walls and beam-and-slab floor floor (roof). Basement walls are made of foundation blocks, with a large number of cracks and chips. The cracks on the facade of the building, on the basement and the tie-beams suggest that the building was allowed to be overloaded, the foundation soil was allowed to soak. Thus, at modeling of an object the consideration was given to geotechnical conditions and possible load excess on the foundation of the building as well as to any man-made impact.

The foundation of the object was simulated by 23 loaded stamps (Fig. 10). For this in making the model of the basement seams have been provided (pos. 2 in Fig. 10) $0.05 \mathrm{~m}$ wide, having reduced strength and deformational properties. The seams simulate present cracks and fractures of the basement foundation blocks.

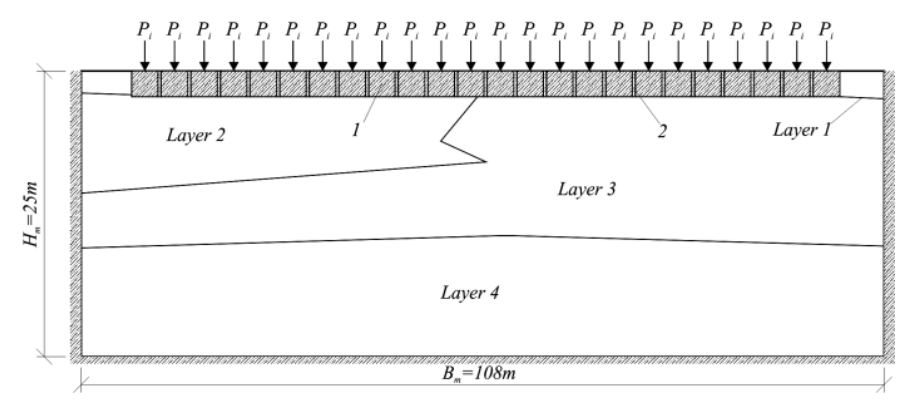

Fig. 10. Calculation model of a real object: 1 - basement of the building; 2 - seam-crack 
As a result of the simulation the predicted values of vertical displacements along the axis of the building were obtained at special geotechnical conditions exceeding the specified load and local reduction of physical and mechanical properties of foundation soils (Fig. 11).

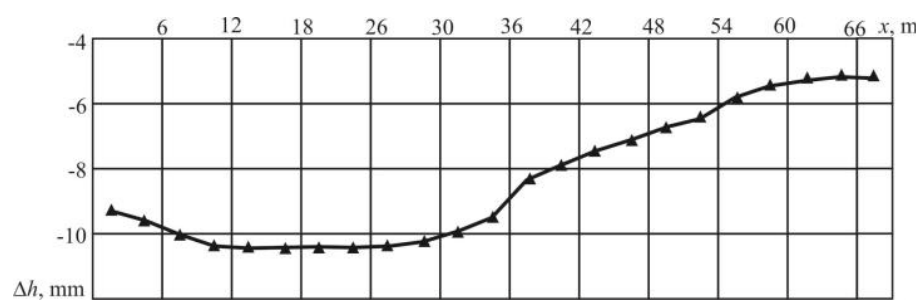

Fig. 11. The graph of changing projected average values of the foundation deformation $\Delta h$

along the longitudinal axis $x$ of the structure

At comparing the calculated and measured deformation values in intervals, the obtained deviation was in the range of $5-25 \%$ at an average value $17 \%$ (Table 2 ).

TABLE II. COMPARISON OF THE CALCULATED AND MEASURED DEFORMATION VALUES

\begin{tabular}{|c|c|c|c|}
\hline Interval, $\mathbf{~ m}$ & $\begin{array}{c}\text { Calculated value, } \\
\mathbf{~ m m}\end{array}$ & $\begin{array}{c}\text { Measured value, } \\
\mathbf{m m}\end{array}$ & Discrepancy, \% \\
\hline $0-10$ & 9.2 & 9.7 & 5 \\
\hline $10-20$ & 10.2 & 9.5 & 7 \\
\hline $20-30$ & 10.1 & 7.8 & 23 \\
\hline $30-40$ & 9.8 & 7.4 & 25 \\
\hline $40-50$ & 7.2 & 5.5 & 24 \\
\hline $50-60$ & 6.1 & 5.5 & 10 \\
\hline $60-71$ & 5.5 & 6.8 & 24 \\
\hline & & Average value: & 17 \\
\hline
\end{tabular}

\section{CONCLUSION}

For the homogeneous soil body under unevenly loaded stamps the monotonic decrease with the depth of vertical stresses and deformations and the formation of zones of maximum horizontal deformations were identified. Also, the dependence of settlement ratios on loads ratios close to the linear one was found. In an inhomogeneous layered soil body, the maximum horizontal deformations and the tensile stresses zone are located within the boundaries of the first weakened layer. The conducted research demonstrate that with the use of computer modeling it is possible with sufficient accuracy to predict the development of non-uniform settlement of buildings and structures, at the same time the cost and time of doing surveying work are considerably reduced.

\section{ACKNOWLEDGEMENT}

The work was created with the support of the T.F. Gorbachev Kuzbass State Technical University. The licensed software complex of geotechnical calculations «Alterra» was presented for a free non-for-profit use by "InhzProektStroi".

\section{REFERENCES}

[1] Ukhov, S. B. Mechanics of soil, bases and foundation: studies for higher education institutions. The 2nd prod., reslave and additional. Moscow: The higher school, 2002. $566 \mathrm{p}$.

[2] Mangushev, R. A. Bases and foundation: the textbook for bachelors of construction. R. A. Mangushev, V. D. Karlov, I. I. Sakharov, A. I. Osokin. Moscow: ABS publishing house; SPB: SPBGASU, 2011. 394 p.

[3] Z. G. Ter-Martirosyan, A. Yu. Mirnyi. Effect of Nonhomogeneity of Soils on their Mechanical Properties. Soil Mechanics and Foundation Engineering. Volume 50. Issue 6. January 2014. pp. 223-231.

[4] E. Özgan, S. Serin, S. Ertürk, I. Vural. Effects of Freezing and Thawing on the Consolidation Settlement of Soils. Soil Mechanics and Foundation Engineering. Volume 52. Issue 5. November 2015. pp. 247-253.

[5] Kouchner, S. G. Calculation of deformations of foundations of buildings and constructions. Zaporizhia: LLC IPO Zaporozhye publishing house. 2008. 496 p.

[6] Ermakova I. A., Bakhayeva S. P., Dyagilev A. V. Numerical modeling of a geomechanical condition of a dump on the water-saturated basis. [Numerical modeling of geomechanical condition of the blade on the basis of water-saturated]. Vestnik of Kuz. state tech. univ. 2014. No. 4. pp. 11-12.

[7] S. G. Bezvolev. General procedure for analysis of the stress-strain state of a soil mass with strengthening or weakening elements. Soil Mechanics and Foundation Engineering. Volume 45. Issue 3. May 2008. pp. 77-86.

[8] A. G. Protosenya, M. A. Karasev. Development of Numerical Model for Deformation Prediction of Soil Mass During Construction of a Moderately Deep Structure in the ABAQUS Software Package. Soil Mechanics and Foundation Engineering. Volume 51. Issue 2. May 2014. pp. 53-59.

[9] A. B. Ponomarev, E. N. Sychkina. Settlement Prediction of Foundations on Argillite-Like Soils (as Exemplified by the Perm' Region). Soil Mechanics and Foundation Engineering. Volume 51. Issue 3. July 2014. pp. 111-116.

[10] Berlinov M. B., Yagupov B. A. Examples of calculation of the bases and bases. Moscow. 2011.

[11] Gorbunov-Posadov M. I., Malikov T. A., Culms V. I. Calculation of designs on the elastic basis. Moscow: Stroyizdat. 1984. 679 p.

[12] Kurlenya, M. V. Technogenic geomechanical fields of tension. M. V. Kurlenya, V. M. Seryakov, A. A. Eremenko. Novosibirsk: Science. 2005. 264 p.

[13] Pokatilov A. V., Prostov S. M., Ivanov S. A. Computer modeling of geomechanical processes at electrochemical fixing of the soil bases of constructions. [Computer modeling of geomechanical processes in the electrochemical induration of soil bases of constructions]. Vestnik of Kuz. state tec. univ. 2013. No. 4. pp. 61-65.

[14] Prostov, S. M., Sokolov M. V. The analysis of the intense deformed condition of the strengthened soil bases on the basis of integrated criteria. [Analysis of stress-strain state of soil bases fixed on the basis of integral criteria]. Vestnik of Kuz. state tec. univ. 2015. No. 6. pp. 52-61.

[15] Sergei M. Prostov, Mikhail V. Sokolov and Andrey V. Pokatilov. The Influence Of Injecting Strengthening For Uniform Subgrade Soils Of Strip Foundations On Their Stress-Strain State. International Journal of Applied 
Engineering Research. Volume 10. Number 25. 2015. pp. 45297-45306.

http://www.ripublication.com/Volume/ijaerv10n24.htm.

[16] Chung W. Experimental and numerical study of soilreinforcement effects on the low-strain stiffness and bearing capacity of shallow foundations. Geotech. Geol. Eng. 2007. N25. pp. 265-281.

[17] A. B. Ponomarev, S. V. Kaloshina. Influence of Slab Foundations Constructed in Dense Urban Settings on Settlement of Existing Buildings. Soil Mechanics and Foundation Engineering. Volume 50. Issue 5. November 2013. pp. 194-199.

[18] V. M. Ulitskii, M. A. Luchkin. Investigation of properties of clayey soils for geotechnical modeling of foundation beds. Soil Mechanics and Foundation Engineering. Volume 43. Issue 6. November 2006. pp. 197-200.
[19] De-luan Feng, Ying-guang. Fang Theoretical and Experimental Study on Multi-Scale Mechanical Properties of Soil. Soil Mechanics and Foundation Engineering. Volume 52. Issue 4. September 2015. pp. 189-197.

[20] V. A. Pshenichkina, S. I. Politov, A. A. Chirkov. Experimental and Theoretical Rationale for Maximum Loading with a Specified Degree of Risk When Simulating the Operation of a "Bed-Foundation-Superstructure" System. Soil Mechanics and Foundation Engineering. Volume 52. Issue 6. January 2016. pp. 311-316.

[21] V. M. Zimin, L. Ya. Bondar. Optimization of Initial Data for Analysis of Beds and Foundations. Soil Mechanics and Foundation Engineering. Volume 52. Issue 1. March 2015. pp. 23-26. 